\title{
A Comparative Study on the Phytochemicals and Antimicrobial Activities of the Hexane Extracts of the Leaves of Tectona Grandis and Its Mistletoe
}

\author{
Uzama Danlami", Okolo Simon \\ Chemistry Advanced Research Centre, Sheda Science and Technology Complex, Garki, Abuja, Nigeria
}

\section{Email address:}

uzamadan@yahoo.com (U. Danlami)

${ }^{*}$ Corresponding author

\section{To cite this article:}

Uzama Danlami, Okolo Simon. A Comparative Study on the Phytochemicals and Antimicrobial Activities of the Hexane Extracts of the Leaves of Tectona Grandis and Its Mistletoe. Frontiers in Heterocyclic Chemistry. Vol. 3, No. 2, 2017, pp. 19-22. doi: $10.11648 /$ j.ajhc.20170302.12

Received: May 17, 2017; Accepted: June 16, 2017; Published: July 25, 2017

\begin{abstract}
A comparative study on the phytochemical constituents and antimicrobial activities of the hexane extracts of the leaves of Tectona grandis and its mistletoe was carried out. The phytochemical screening was carried out by adopting standard methods. Agar well diffusion method was employed for the antimicrobial screening of the extracts of the leaves of Tectona grandis and its mistletoe. The phytochemical screening results of hexane extract of Tectona grandis leaves revealed the presence of steroids, glycosides, saponins, terpenoids, flavonoids, cardiac glycosides and volatile oils, while the hexane extract of the mistletoe leaves revealed the presence of steroids, terpenoids, saponins, glycosides and cardiac glycosides. For the antimicrobial activities screening, the results revealed the hexane extract of the mistletoe leaves to have greater zone of inhibition in Staphylococcus aureus (24mm), Escherichia coli (26mm), Salmonella typhi (20mm) and Pseudomonas aeriginosa $(12 \mathrm{~mm})$ than the hexane extract of the Tectona grandis leaves in Staphylococcus aureus (16mm), Escherichia coli (13mm), Salmonella typhi $(18 \mathrm{~mm})$ and Pseudomonas aeriginosa $(10 \mathrm{~mm})$. The hexane extracts of the leaves of Tectona grandis and its mistletoe were not active on the Klebsiella pneumonia. The result of the antimicrobial screening showed the extracts of the leaves of the mistletoe to be more active than the leaves of Tectona grandis. The leaf extracts of Tectona grandis and its mistletoe can serve as antibiotics in ethno medicine.
\end{abstract}

Keywords: Tectona Grandis, Mistletoe, Antibiotics, Steroids, Phytochemical Screening, Hexane Extracts

\section{Introduction}

Tectona grandis is a large tree which grows to $40-50 \mathrm{~m}$ in height and has large papery leaves $30-60 \mathrm{~cm}$ in length, that are often hairy on the lower surface. It has small fragrant white flowers.

Tectona grandis is a genus of tropical hard wood trees which belongs to the family Lamiacea. There are three species, often collectively called teak. These are: Tectona grandis (common teak), Tectona hamitoniana (Dahat teak) and Tectona philippinesis (philippine teak), among which Tectona grandis is by far the most important [1].

Tectona grandis can be found in Asia, India/Pakistan, Bangladesh, Burma, Indonesia, Thailand, Nigeria, Philippines, China and Malaysia.

It is widely cultivated in other tropical areas, as its wood is moderately hard, easily worked, and extremely durable [2].

The wood contains an essential oil that resists the action of water and prevents the rusting of iron. The heartwood is resistant to termites. Tectona grandis is superior to all other woods for ship building and is also used for forniture, flooring and general construction.

The leaves and other parts of the tree are used as diuretics, laxative, sedetive, expectorant, anthelmintic, antiinflammatory, antibacterial, cytotoxic, antianemic, antiulcer, antiviral, menstrual disorders, heamorrhages, sorethroat, dyspepsia and burning of stomach caused by bile over flow, vermifuge, strengthening of sight, treatment of pile, dysentery, antidiabetic, antioxidant, antipyretic, as dye and incense [3].

Mistletoe are hemiparasitic plants that attach to and penetrate the branches of a tree or shrub by a structure called 
the haustorium, through which they absorb water and nutrients from the host plant. The name mistletoe originally referred to the species Viscumalbum. A family of Loranthaceae. The leaves are tongue-shaped, broader towards the end, 1 to 4 inches long, very thick and leathery, arranged in pairs, with very short footstalks. Mistletoe is an excellent medicinal herb. It has been used for hypertension, headaches, menopausal symptoms, infertility, arthritis, rhematism, cough and asthma [2].

A study on the comparison of antibacterial activity of leaves extracts of Tectona grandis, Mangifera indica, and Anacardium occidentale was carried out [4]. Also a study was carried out on the synergistic invitro antibacterial activity of Tectona grandis leaves with tetracycline [5].

The present research was designed to carry out a comparative study on the phytochemicals and Antimicrobial activities of the hexane extracts of the leaves of Tectona grandis and its mistletoe.

\section{Materials and Methods}

\subsection{Collection of Plant Material}

The leaves of Tectona grandis and its mistletoe were collected from Sheda Science and Technology Complex (SHESTCO), Abuja, Nigeria. The plant was identified and authenticated at the herbarium unit of the Department of Biological Sciences, Ahmadu Bello University, Zaria, Nigeria. The leaves were collected and dried for two weeks under shed. The dried leaves were powdered using a grinding machine and sieved with a mesh of size $0.5 \mathrm{~mm}$. The powdered sample obtained was stored in a clean air tight container at ambient temperature until when needed for use.

\subsection{Preparation of Extracts}

The powdered plant sample was extracted using hexane. $200 \mathrm{~g}$ of the sample was packed in a muslin cloth and inserted into soxhlet extractor and hexane was used as the extraction solvent for a period of eight hours. At the end of the period, the solvent was recovered by rotary evaporator and the extract was collected. The extract was placed in a desicator for some times before analysis.

\subsection{Phytochemical Analysis}

Standard methods were adopted for the phytochemical screening of the extracts of Tectona grandis and its mistletoe leaves [6] [7] [8].

\subsubsection{Test for Steroids}

Chloroform $(2 \mathrm{ml})$ was added to the extract $(0.2 \mathrm{~g})$ then concentrated tetraoxosulphate (vi) acid (2ml) was added. Themixture was shaken for five minutes and allowed to stand for thirty minutes. Appearance of red colour at the lower layer indicated the presence of steroids.

\subsubsection{Test for Tannins}

Distilled water $(10 \mathrm{ml})$ was added to the extract $(5 \mathrm{~g})$, this was stirred and filtered. To the filtrate was added Ferric chloride reagent. The formation of a blue-green precipitate indicated the presence of tannin.

\section{Test for Glycosides}

Dilute tetraoxosulphate (vi) acid $(5 \mathrm{ml})$ was added to the extract $(0.2 \mathrm{~g})$. The mixture was heated for 15 minutes. Fehling solution A and B was then added and the resulting mixture was heated for 15 minutes. The formation of a brick red precipitate indicated the presence of glycosides.

\subsubsection{Test for Saponins}

Distilled water $(5 \mathrm{ml})$ was added to the extract $(0.2 \mathrm{~g})$. This was shaken for 30 minutes. The formation of frothing, appearance of creamy mist of small bubbles, indicated the presence of saponins.

Test for Phenols

To the extract $(0.5 \mathrm{~g})$ was added $1 \%$ Ferric (iii) chloride in methanol/water (1:1).A dirty green precipitate indicated the presence of phenols.

\subsubsection{Test for Alkaloids}

Hydrochloric acid solution $(1 \%, 5 \mathrm{ml})$ was added to the extract $(0.5 \mathrm{~g})$. This was stirred on water bath and then filtered. To the filtrate was added Mayer's reagent. The formation of a white precipitate indicated the presence of alkaloids.

\section{Test for Terpenoids}

Acetic anhydride $(0.5 \mathrm{ml})$ was added to the extract $(1 \mathrm{ml})$, then concentrated tetraoxosulphate (vi) acid $(0.5 \mathrm{ml})$ was added. The formation of a bluish green precipitate indicated the presence of terpenoids.

\subsubsection{Test for Carbohydrates}

To the extract $(2 \mathrm{ml})$ was added a mixture of equal volume $(5 \mathrm{ml})$ of Fehling's solution A and B. The mixture was boiled for 3 minutes. A brick red precipitate indicated the presence of Carbohydrates.

Test for Flavonoids

Dilute sodium hydroxide solution $(2 \mathrm{ml})$ was added to the extract $(0.2 \mathrm{~g})$, then concentrated Hydrochloric acid $(2 \mathrm{ml})$ was added. A yellow colour was formed which turned colourless. This indicated the presence of flavonoids.

\subsubsection{Test for Cardiac Glycosides}

The extract $(0.5 \mathrm{~g})$ was dissolved in glacial acetic acid ( $2 \mathrm{ml})$ which contained a drop of Ferric chloride solution. Concentrated tetraoxosulphate (vi) acid $(2 \mathrm{ml})$ was added by the sides of the container. The formation of a brown ring indicated the presence of Cardiac glycosides.

\subsubsection{Test for Resins}

To the extract $(0.2 \mathrm{~g})$ was added Acetic anhydride $(3 \mathrm{ml})$, then concentrated tetraoxosulphate (vi) acid $(2 \mathrm{ml})$ was added. 
The formation of violet colouration indicated the presence of resins.

\section{Test for Balsams}

Alcoholic Iron (iii) chloride $(3 \mathrm{ml})$ was added to the extract (4ml).This was then warmed. The formation of a dark green colouration indicated the presence of Balsams.

\subsubsection{Test for Volatile Oils}

Dilute sodium hydroxide solution $(2 \mathrm{ml})$ was added to the extract $(4 \mathrm{ml})$, then Hydrochloric acid $(0.1 \mathrm{M}, 2 \mathrm{ml})$ was also added and the mixture was shaken for 5minutes. The formation of a white precipitate with volatile oils indicated the presence of volatile oils.

\subsection{Antimicrobial Screening}

\subsubsection{Source of Test Organisms}

The pure culture of clinical isolates of bacteria used for the screening were obtained from University of Abuja Teaching Hospital, Gwagwalada, Abuja, Nigeria. These include: Escherichia coli, Staphylococcus aureus, Salmonella typhi, Klebsiella pneumonia and Pseudomonas aeriginosa.

\subsubsection{Culture Media}

Mueller Hinton agar (MHA) was used for the antibacterial sensitivity test. It was prepared according to the manufacturer's instruction. The screening was carried out in Biotechnology Advanced Research Centre, Sheda Science and Technology Complex (SHESTCO), Sheda, Abuja, Nigeria.

\subsubsection{Antibacterial Activity}

The activities of hexane extract of the leaves of Tectona grandis and its mistletoe were evaluated on Salmonella typhi, Escherichia coli, Staphylococcus aureus, Klebsiella pneumonia and Pseudomonas aeriginosa using agar well diffusion method [9] [10] [11]. The isolates were allowed to grow for 24 hours at $37^{\circ} \mathrm{C}$ on Mueller Hinton Broth (MHB).

Wells were bored into the agar media using a sterile $6 \mathrm{~mm}$ cork borer, the wells were then filled up with $0.2 \mathrm{ml}$ of the various concentration of the extract. The plates were allowed to stand in the lamina flow hood for 30 seconds to allow proper diffusion of the extract. The Bacteria plates were incubated at $37^{\circ} \mathrm{C}$ for 24 hours. Streptomycin was used as a positive control and Dimethylsulphoxide (DMSO) as a negative control.

\section{Results and Discussions}

\subsection{Phytochemical Analysis}

The result of the phytochemical analysis of the Hexane extracts of Tectona grandis and its mistletoe leaves is given in Table 1.The result indicated the presence of steroids, glycosides, saponins, terpenoids, flavonoids, cardiac glycosides and volatile oils in the hexane extract of Tectona grandis but the presence of steroids, terpenoids, saponins, glycosides and cardiac glycosides in the hexane extract of mistletoe leaves. The active compounds detected in the extracts are known to possess medicinal properties, which may be responsible for the antimicrobial activities of the tested compounds. Saponins exhibits cytotoxic effect and growth inhibition against a variety of cells. Its presence in the leaves of Tectona grandis and mistletoe makes them to possess antiinflammatory and anticancer properties.

Table 1. Phytochemical analysis of the Hexane extracts of Tectonagrandis and itsistletoe leaves.

\begin{tabular}{lll}
\hline Phytochemicals & $\begin{array}{l}\text { Tectonagrandis } \\
\text { leavesHexane extract }\end{array}$ & $\begin{array}{l}\text { Mistltoe leaves } \\
\text { Hexane extract }\end{array}$ \\
\hline Steroids & + & + \\
Glycosides & + & + \\
Saponins & + & + \\
Phenols & - & - \\
Alkaloids & - & - \\
Terpenoids & + & + \\
Carbohydrates & - & - \\
Flavonoids & + & - \\
Cardiac glycosides & + & + \\
Resins & - & - \\
Balsams & - & - \\
Tannins & - & - \\
Volatile oils & + & - \\
\hline
\end{tabular}

$+=$ present,$=$ absent

\subsection{Antimicrobial Activities}

The result of the antibacterial activities of hexane extract of Tectona grandis and its mistletoe leaves is given in Table 2.The result revealed that the hexane extract of mistletoe leaves exhibited the following zone of inhibition against Staphylococcus aureus (24mm), Escherichia coli (26mm), Salmonella typhi $(20 \mathrm{~mm})$ and Pseudomonas aeriginosa $(12 \mathrm{~mm})$, while the hexane extract of Tectona grandis leaves exhibited the following zone of inhibition against Staphylococcus aureus (16mm), Escherichia coli (13mm), Salmonella typhi $(18 \mathrm{~mm})$ and Pseudomonas aeriginosa (10mm).

The activities of the extracts was based on the zone of inhibition.The greater the zone of inhibition, the more active the extract was. The extract of the mistletoe has greater zone of inhibition against Staphylococcus aureus, Escherichiacoli, Salmonella typhi and Pseudomonas aeriginosa than Tectona grandis. This showed that the mistletoe leaves have more antibacterial action than the Tectona grandis leaves. The range of inhibition of the hexane extract was between $10 \mathrm{~mm}$ to $26 \mathrm{~mm}$. The degree of antibacterial activities of the hexane extract of mistletoe compared favorably well with that of the standard antibiotics (Streptomycin). This result showed that the extracts can serve as potential antibiotics for the management of diseases caused by Escherichia coli, Staphylococcus aureus, Salmonella typhi and Pseudomonas auriginosa. 
Table 2. Antibacterial activities of hexane extracts of Tectonagrandis and its mistletoe leaves.

\begin{tabular}{lllllll}
\hline \multirow{2}{*}{ Bacteria } & \multirow{2}{*}{ Extract } & \multicolumn{2}{c}{ Concentration in $\mathbf{~ m g} / \mathbf{m l}$ (zone of inhibition in mm) } & $\begin{array}{l}\text { Positive control Streptomycin } \\
\text { (zone of inhibitionin mm) }\end{array}$ & $\begin{array}{l}\text { Negative control } \\
\text { DMSO }\end{array}$ \\
\cline { 3 - 5 } & & $\mathbf{8 5 0}$ & $\mathbf{7 5 0}$ & $\mathbf{6 5 0}$ & 27 & NA \\
\multirow{2}{*}{ Escherichia coli } & HXN MTL & 2 & 23 & 21 & 26 & NA \\
\multirow{2}{*}{ Staphylococcusaureus } & HXN TCN & 13 & 11 & 9 & 26 & NA \\
\multirow{2}{*}{ Salmonella typhi } & HXN MTL & 24 & 20 & 18 & 27 & NA \\
& HXN TCN & 16 & 15 & 13 & 28 & NA \\
\multirow{2}{*}{ Pseudomonasaeriginosa } & HXN MTL & 20 & 17 & 15 & 27 & NA \\
& HXN TCN & 18 & 16 & 15 & 26 & NA \\
& HXN MTL & 12 & 10 & 7 & 26 & NA \\
\hline
\end{tabular}

$\mathrm{HXN}=$ Hexane, $\mathrm{DMSO}=$ Dimethylsulphoxide, $\mathrm{MTL}=$ Mistletoe $\mathrm{TCN}=$ Tectona, $\mathrm{N}$ A $=$ No activity

\section{Conclusion}

The leaves of Tectona grandis and its mistletoe have the potency of antibacterial activity as revealed by the presence of the secondary metabolites in them. The results of the antimicrobial study revealed the leaves of the mistletoe to be more active than the leaves of Tectona grandis.

\section{References}

[1] Kirtikar K. R. and Basu B. D. (1987).Indian medicinal plants, Bishen Sing Mahendra PalSing, Dehidun, Indian, 2(1):12641265 .

[2] Uzama D. and Envuladu P. E. (2017).A comparative study on the phytochemicals and Antimicrobial activities of the ethanol and petroleum ether extracts of the leaves of Albizia lebbeck and its mistletoe, International Journal of Pharmacy and Chemistry, 3(2):13-18.

[3] Mahesh G. and Vijay N. (2009). Effect of Tectona grandis on dexanethasone-inducedinsulin resistance in mice, Journal of Ethnopharmacology, 122(2):304 - $307 . \quad$ doi: 10.1016/1jep.2009.01, .008.

[4] Krishnananda K. K. and Ramakrishna S. A. (2016). Comparison of antibacterial activity of leaves extracts of Tectona grandis, Mangifera indica and Anacardium occidentale, Int. J. Curr. Pharm. Res. 9(1):36 - 39.
[5] Purushotham K. G. and Arun P. (2010). Synergistic invitro antibacterial activity of Tectona grandisleaves with tetracycline, International Journal of Pharm. Tech. Research. CODEN (USA): IJPRIFISSN: 0974-4304. 2(1):519-523.

[6] Trease G. E. and Evans W. C. (2002). Pharmacognosy. 15th Edition, Sauders Publishers, London, pp42-44.

[7] Uzama D. (2009). Phytochemical screening and Antibacterial activity of Guava (PsidiumguajavaL.) crude extracts, Biological and Environmental Science Journal for the Tropics. 6(4):139-142.

[8] Sofowora A. (1993).Screening plants for bioactive agents, In: Medicinal plants and traditional medicine in Africa. 2nd Edition, spectrum booksLtd. pp 134-156.

[9] Igbinosa O. O., Igbinosa E. O. and Aiyegoro O. A. (2009). Antimicrobial activity and phytochemical screening of stem bark extracts from Jatropha curcas (linn). African Journal of Pharmacy. 3(2): 058-062.

[10] Uzama D., Osuagwu E. C. and Osuagwu M. I. (2017). Evaluation of the phytochemical and Antimicrobial activities of the ethanolic, hexane and ethyl acetate extracts of Spigelia anthelmia leaves. International Journal of Pharmacy and Chemistry. 3(3):29-32.

[11] Uzama D., Gubele J. D., Bwai M. D. and Kabir M. G. (2015). Phytochemical, Nutritional and Antimicrobial screening of hexane, ethylacetate and ethanolic extracts of Boswellia Dalzielii leaves and bark. American J. Biosci. and Bioeng. $3(5): 76-79$ 